\title{
Outdoor Workers Exposed to Solar Radiation: A Spotlight on Immunomodulation
}

\author{
Carlo Grandi and Maria Concetta D'Ovidio* \\ Department of Occupational and Environmental Medicine, Epidemiology and Hygiene, Italian Workers' Compensation \\ Authority (INAIL), Monte Porzio Catone, Rome, Italy
}

*Corresponding author: Maria Concetta D'Ovidio, Department of Occupational and Environmental Medicine, Epidemiology and Hygiene, Italian Workers' Compensation Authority (INAIL), Monte Porzio Catone, Rome, Italy

\author{
ARTICLE INFO \\ Received: 画 August 13, 2019 \\ Published: 蔧 August 21, 2019 \\ Citation: Carlo Grandi, Maria Concetta \\ D'Ovidio. Outdoor Workers Exposed to \\ Solar Radiation: A Spotlight on Immu- \\ nomodulation. Biomed J Sci \& Tech Res \\ 20(5)-2019. BJSTR. MS.ID.003501.
}

\section{ABSTRACT}

In outdoor occupational settings workers are exposed to several agents including solar radiation. The last one may induce short and long-term effects on both skin and eye and may exert a local (skin) as well as a systemic suppression of the immune response. A careful assessment of health risks due to exposure to solar radiation in outdoor workers is requested and an appropriate health surveillance has to be implemented, paying great attention to the study of the immune profile. Moreover, the implementation of preventive and protective measures, including education and training, is of paramount importance.

Keywords: Solar Radiation; Outdoor Workers; Immune System; Occupational Health

\section{Introduction}

Outdoor workers may be exposed to several physical, chemical and biological agents, which, by alone or in combination, may induce adverse health effects or exacerbate pre-existing clinical conditions. A lot of working activities are conducted outdoor, especially those related to agriculture/forestry, construction, fishing and maintenance of outdoor infrastructures [1]. Solar Radiation (SR) is a ubiquitous risk factor for outdoor workers. At ground level SR composition includes about $50 \%$ of infrared radiation, $45 \%$ of visible radiation and only $5 \%$ of Ultraviolet (UV) radiation.

The last component, although present in small amounts, is the most critical for human health, being associated with several acute and chronic effects [2,3]. In Europe, about 15 million workers are employed in outdoor activities and, although exposure to SR may cause serious adverse health effects on skin and eye [3-5], the risk is underestimated. The immunosuppressive effect of SR is due to the UV component and represents another critical feature in this regard. Local or systemic suppression of the immune system by UV radiation may, for instance, inhibit cell-mediated immune responses [6,7] and re-activate latent infections such as those due to herpes simplex and human papilloma viruses [8-10]. A key question is the vaccination's effectiveness, as a reduction of the immune response to vaccines following UV radiation exposure was shown in experimental animal models [7]. Local (skin) and systemic immunosuppressive effects of solar UV radiation may conversely result into beneficial effects, for instance inhibiting autoimmune reactions [11]. Vitamin D activation is one of the beneficial effects of exposure to solar UV radiation, but other beneficial health effects due to SR are recognized or speculated, including circadian rhythms regulation, promotion of general wellbeing, blood pressure lowering and reduction of the risk for some internal cancers $[1,12]$.

Balancing potential detrimental and beneficial health effects of exposure to SR for outdoor workers at individual level is likely to go beyond the present scientific knowledge, but will be essential for an appropriate risk management, i.e. for a suitable implementation of both preventive and protective measures. Immune system modulation by SR plays a key role in this regard.

\section{Discussion}

On the basis of the experimental and epidemiological evidence concerning effects on skin and eye as well as immunomediated effects of SR [1,7-11,13], for an appropriate risk assessment and management in the outdoor activities it is crucial to determine the level of exposure to SR of the individual worker, types and levels of co-exposure to other physical, chemical and biological agents as well as phototype, health features and immunological status of the worker. Exposure to SR, specifically to the UV component, is largely dependent on time of day, season, latitude, altitude, atmospheric pollution, time spent in outdoor activities, environmental albedo and shieldings, use of individual protective 
means [14,15]. Preventive and protective measures imply the assessment of individual exposure to solar UV radiation (it should also be important to assess long term cumulative exposure) and include compliance with exposure limits (when feasible), reduction of overall exposure duration, avoidance of sun in the central hours (if possible), use of sunscreens, sunglasses and appropriate clothing, health surveillance $[16,17]$. However, their combination may be different in different exposure situations and for different individual susceptibilities. Moreover, if personal protection is requested against multiple risk factors, the pertinent protective measures have to be harmonized.
We suggest more attention to the study of the immune profile of the individual worker during health surveillance, given the multifunctional role of the immune system and the immunomodulatory properties of several physical, chemical and biological agents (including SR) present in outdoor settings. We also remark the importance of information and training not only as a part of preventive measures against occupational hazards in a strict sense, but as an essential step to promote healthy lifestyles. A summary view of the key points discussed in this paper and some additional indications are given in Figure 1.

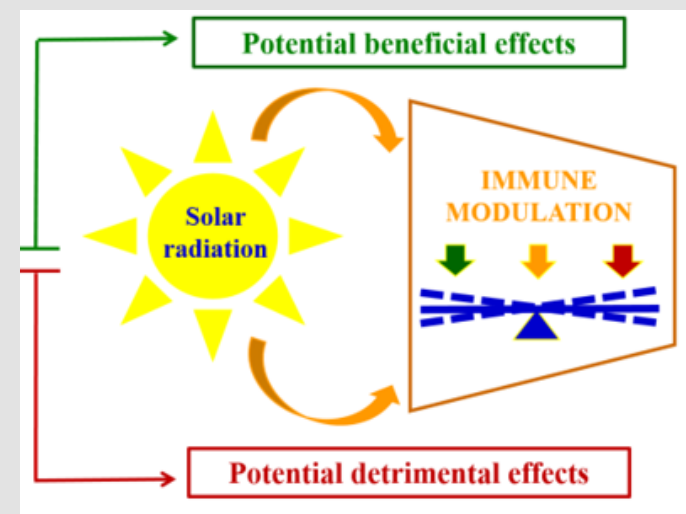

SOME KEY POINTS OF CONCERN FOR THE MANAGEMENT OF EXPOSURE TO SOLAR RADIATION

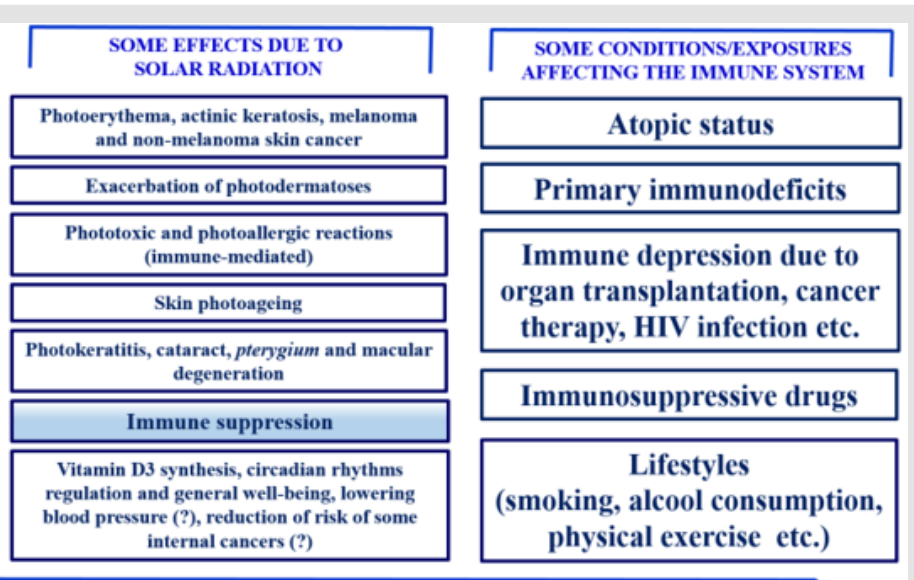

physical exercise etc.)

\footnotetext{
- The protection of outdoor workers against the effects due to solar radiation needs a careful assessment of all the factors involved, including co-exposures to physical, chemical and biological agents.

- The preventive and protective measures should include reduction of the overall exposure duration, avoidance of the sun in the central hours when possible, sunscreens, sunglasses, appropriate clothing, health surveillance.

- The level of protection has to be possibly set on the basis of a balance between adverse and potential beneficial health effects, assuring adequate information and training of the workers.

- The immune profile of the worker is a primary step to be recognized during the health surveillance, paying attention to conditions of mild immune depression. Individual features regarding pathological conditions and lifestyles have to be scrupulously assessed.
}

Figure 1: Features related to solar radiation exposure in outdoor workers (partially inspired by: Grandi C, D'Ovidio MC (2018) The interplay between solar radiation, climate change and immunotoxicants in relation to immune response modulation: A concern for outdoor workers' health. Am J Health Res 6:138-149).

\section{References}

1. Grandi C, D'Ovidio MC (2018) The interplay between solar radiation, climate change and immunotoxicants in relation to immune response modulation: A concern for outdoor workers' health. Am J Health Res 6 : 138-149.

2. (1992) International Agency for Research on Cancer. Solar and ultraviolet radiation, volume 55. IARC monographs on the evaluation of carcinogenic risks to humans. IARC, Lyon, France.

3. Modenese A, Korpinen L, Gobba F (2018) Solar radiation exposure and outdoor work: An underestimated occupational risk. Int J Environ Res Public Health 15; 2063

4. Paulo MS, Adam B, Akagwu C, Akparibo I, Al-Rifai RH, et al. (2019) WHO/ ILO work-related burden of disease and injury: Protocol for systematic reviews of occupational exposure to solar ultraviolet radiation and of the effect of occupational exposure to solar ultraviolet radiation on melanoma and non-melanoma skin cancer. Environ Int 126: 804-815.

5. Tenkate T, Adam B, Al-Rifai RH, Chou BR, Gobba F, et al. (2019) WHO/ ILO work-related burden of disease and injury: Protocol for systematic reviews of occupational exposure to solar ultraviolet radiation and of the effect of occupational exposure to solar ultraviolet radiation on cataract. Environ Int 125: 542-553.

6. Swaminathan A, Harrison SL, Ketheesan N, van den Boogaard CHA, Dear K, et al. (2019) Exposure to solar UVR suppresses cell-mediated immunization responses in humans: The australian ultraviolet radiation and immunity study. J Invest Dermatol 139: 1545-1553.

7. Norval M, Halliday GM (2011) The consequences of UV-induced immunosuppression for human health. Photochem Photobiol 87: 965977.

8. Norval M (2006) The effect of ultraviolet radiation on human viral infections. Photochem Photobiol 82: 1495-1504.

9. Ichihashi M, Nagai H, Matsunaga K (2004) Sunlight is an important causative factor of recurrent herpes simplex. Cutis 74: 14-18.

10. Hrushesky WJ, Sothem RB, Reitveld WJ, Du-Ouiton J, Boon ME (2006) Sun exposure, sexual behaviour and uterine cervical human papilloma virus. Int J Biometereol 50: 167-173.

11. Halliday GM, Damian DL, Rana S, Byrne SN (2012) The suppressive effects of ultraviolet radiation on immunity in the skin and internal organs: Implications for autoimmunity. J Dermatol Sci 66: 176-182. 
12. Cranney A, Horsley T, O’Donnell S, Weiler H, Puil L, et al. (2007) Effectiveness and safety of vitamin D in relation to bone health. Evid Rep Technol Assess (Full Rep) 158: 1-235.

13. Lucas RM, Yazar S, Young AR, Norval M, de Gruijl FR, et al. (2019) Human health in relation to exposure to solar ultraviolet radiation under changing stratospheric ozone and climate. Photochem Photobiol Sci 18 641-680.

14. (2012) International Agency for Research on Cancer. Radiation, volume 100D. A review of human carcinogens. IARC monographs on the evaluation of carcinogenic risks to humans. IARC, Lyon, France.

ISSN: 2574-1241

DOI: 10.26717/BJSTR.2019.20.003501

Maria Concetta D’Ovidio. Biomed J Sci \& Tech Res

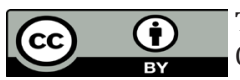

This work is licensed under Creative Commons Attribution 4.0 License

Submission Link: https://biomedres.us/submit-manuscript.php
15. Milon A, Sottas PE, Bulliard JL, Vernez D (2007) Effective exposure to solar UV in building workers: Influence of local and individual factors. J Exp Science Environ Epidem 17: 58-68.

16. International Commission on Non Ionizing Radiation Protection (2010) ICNIRP statement - protection of workers against ultraviolet radiation. Health Phys 99: 66-87.

17. Modenese A, Bisegna F, Borra M, Grandi C, Gugliermetti F, et al. (2016) Outdoor work and solar radiation exposure: Evaluation method for epidemiological studies. Medycyna Pracy 67: 577-587.

$\begin{array}{ll}\text { BIOMEDICAL } & \text { Assets of Publishing with us } \\ \text { RESEARCHES } & \text { - Global archiving of articles } \\ \text { - Immediate, unrestricted online access } & \text { - Rigorous Peer Review Process } \\ & \text { - Authors Retain Copyrights }\end{array}$

